\title{
Snapshot of proton pump inhibitors prescriptions in a tertiary care hospital in Switzerland: less is more?
}

\author{
Camille Lenoir $^{1}\left[\right.$ D Myriam El Biali ${ }^{1} \cdot$ Christophe Luthy $^{2} \cdot$ Olivier Grosgurin $^{3} \cdot$ Jules Alexandre Desmeules $^{1}$. \\ Victoria Rollason ${ }^{1}$
}

Received: 29 April 2019 / Accepted: 17 October 2019 / Published online: 29 October 2019

(c) The Author(s) 2019

\begin{abstract}
Background Proton pump inhibitors are among the most widely prescribed drugs in the world, but more than half of the indications for prescription are unjustified. The misuse of this therapeutic class has heavy consequences such as additional health costs, adverse drug reactions following long-term use and gastric acid rebound when the proton pump inhibitor is discontinued. Objective The overprescription of proton pump inhibitors is therefore becoming a public health problem, which led us to evaluate their use within the Geneva University Hospitals. Setting Patients hospitalized in two divisions of the department of internal medicine of the Geneva University Hospitals on a single day. Methods This is a register-based cross-sectional study and it collected data about the prescription pattern of proton pump inhibitors by consulting the electronic records of patients included. Main outcome measure To determine if the proton pump inhibitors prescription is made according to the market authorization and the available guidelines. Results Hundred-eighty patients were included. 54\% of patients were on proton pump inhibitors, $29 \%$ of whom had their treatment initiated at hospital. Of the indications for treatment, $72 \%$ were not justified and $63 \%$ of the justified indications did not have an adequate dosage. Therefore, in all patients with a proton pump inhibitor at hospital, only $11 \%$ had a justified indication with an adequate dose. Finally, $87 \%$ of known home prescriptions were renewed on admission and among them, $71 \%$ did not have a justified or possibly justified indication according to the guidelines. Conclusion Indication for treatment inside the hospital was not justified in $72 \%$ of patients and only $11 \%$ had a justified indication with an adequate dosage. Precise guidelines with evidence-based indications and adequate daily doses would help to correctly prescribe proton pump inhibitors. Moreover, patients should benefit from a thorough evaluation of their treatment.
\end{abstract}

Keywords Drug-safety $\cdot$ Pharmacoepidemiology $\cdot$ Prescribing $\cdot$ Proton pump inhibitors $\cdot$ Public health $\cdot$ Switzerland · Tertiary care centers

\section{Impact of findings on practice statements}

Camille Lenoir

camille.lenoir@hcuge.ch

1 Department of Anesthesiology, Pharmacology, Intensive Care, and Emergency Medicine, Division of Clinical Pharmacology and Toxicology, Geneva University Hospitals and University of Geneva, Rue Gabrielle-Perret-Gentil 4, 1205 Geneva, Switzerland

2 Department of Rehabilitation and Geriatrics, Division of General Medical Rehabilitation, Geneva University Hospitals and University of Geneva, Avenue de Beau-Séjour 26, 1206 Geneva, Switzerland

3 Department of Medicine, Division of Internal General Medicine, Geneva University Hospitals, Rue Gabrielle-Perret-Gentil 4, 1205 Geneva, Switzerland
- Around $70 \%$ of the renewed prescriptions for proton pump inhibitors on admission did not have a justified indication.

- As many as $72 \%$ of the hospitalised patients had an unjustified indication for a proton pump inhibitor.

\section{Introduction}

Proton pump inhibitors (PPIs) were introduced to the market at the end of the 1980s [1] and are currently among the most widely prescribed treatments worldwide [2], with 
more than $60 \%$ of them prescribed for an unjustified indication [3] in US ambulatory settings. The chronic use of PPIs, the difficulty in stopping the treatment due to gastric acid rebound symptoms [4], their effectiveness and their very good short-term tolerance, leading to an estimated compliance of $71 \%$, explain the magnitude of their prescription [5].

In the US among others, PPIs are therefore associated with a problem of overuse [6], despite clearly established prescription guidelines, evidence of adverse effects in the case of prolonged intake and additional cost incurred [7]. In Switzerland, there are similar concerns and indeed the better usage of PPIs is part of a national campaign for the reduction of PPI overuse, the "Smarter Medicine" campaign, set up by the Swiss Society of Internal Medicine [8].

A prospective study performed in a department of internal medicine in France showed that only 33\% of the indications were within the scope of the marketing authorization. Amongst the $67 \%$ of off-label prescriptions, $69 \%$ of PPIs were given as a prevention against potential gastrointestinal lesions when an antiplatelet drug, a corticosteroid or an anticoagulant was prescribed and this in subjects without any risk factor for digestive haemorrhage [5]. This study also found that PPI prescription increased significantly with age, with more than half of the patients aged 70-79 years old receiving a PPI [5].

The most common misuse of PPIs is their use for the prophylaxis of stress ulcers outside the intensive care unit (ICU) [9]. A study conducted in the US on non-ICU patients showed that $79 \%$ did not have any risk factor for a stress ulcer and therefore received an unjustified PPI prophylaxis [10].

The misuse of PPIs can also be measured by the use of an inappropriate dosage. The recommendations for esomeprazole as a prophylaxis are $20 \mathrm{mg}$ per day in almost all indications, while the $40 \mathrm{mg}$ daily dose is commonly prescribed, without any demonstrated benefit [11].

Whereas short-term use is generally well tolerated, the over-use of PPIs may also be related to the lack of awareness of the harmful effects of their long-term use. Prolonged PPI intake is associated with an increased total risk of fractures $[4,12,13]$, although a small recent study shows that long-term PPI use does not appear to promote changes in bone mineral density and strength that could predispose to fractures [14]. Also, a recent retrospective cohort study does not evidence an association between PPI use and fracture risk among older adults [15]. PPI intake is also associated with an increased total risk of nosocomial [16] and community-acquired pneumonia [17], and intestinal infections $[18,19]$ by Clostridium difficile, Shigella, Campylobacter and Salmonella [20]. These intestinal infections could be explained by the fact that PPIs modify the gut microbiota as shown in several studies [21, 22]. A recent study on over-the-counter (OTC) PPI use shows no association with pulmonary and intestinal infections. However, in this study, the PPIs were taken at a lower dose and for a shorter period of time compared to other studies [23]. In addition, PPIs are among the drugs commonly associated with the occurrence of tubulointerstitial nephritis [24], which may lead to acute renal failure [25]. Longterm treatment with PPIs may also induce deficiencies in vitamin B12, iron, and magnesium [26, 27]. Moreover, a population based study demonstrated that long-term PPIs use, even after $H$. pylori eradication therapy, is associated with an increased risk of gastric cancer [28], though this study was not in line with a previous meta-analysis [29].

PPI prescription can also lead to drug interactions. The absorption of other drugs may be influenced by the increased gastric $\mathrm{pH}$ associated with the intake of PPIs [4], resulting in either an increase but also a decrease in the absorption of these concomitant drugs. In addition, several PPIs have inhibitory effects on different cytochromes, in particular on CYP2C19 and 3A4 and on the P-gp transport system [30]. From a pharmacodynamic point of view, some authors have raised concerns about the prescription of PPIs with aspirin, claiming a reduced cardioprotective effect of aspirin. This could be due to a reduced absorption of aspirin but also to a reduced platelet response through increased serum thromboxane $\mathrm{B} 2$, and therefore also endogenous thromboxane $\mathrm{A} 2$ [31].

A database study from 2016 demonstrates that the PPI use in UK general practices increased between 1990 and 2014 and that $60 \%$ of long-term users did not attempt to discontinue or step down the dose [32]. These data suggest that the re-evaluation of the adequacy of the PPI treatment was not done although patients should benefit from a reconsideration of the usefulness of their treatment on a regular basis. This study highlights the need of a "Smarter Medicine" and the validity of the campaign mentioned above. The authors advance that by improving withdrawal strategies, a reduction of the costs and the occurrence of adverse effects should be possible [32].

Esomeprazole is the most widely used PPI at the Geneva University Hospitals. The hospital benefits from attractive prices, but this hospital prescription influences the community prescription, participating in an estimated extra cost of 30.3 million euros between 2000 and 2008 [33]. In Switzerland, esomeprazole is not an OTC so PPIs intake comes from medical prescription. 


\section{Aim of the study}

The aim of our prospective study was to understand the PPI prescription in the department of internal medicine of our hospital and in particular to determine if the PPI prescription is made according to the market authorization and the available guidelines.

\section{Ethics approval}

All procedures performed in our study were in accordance with the ethical standards of the regional research ethics committee of the canton of Geneva (No. 2016-00580) and with the 1964 Helsinki declaration and its later amendments or comparable ethical standards.

\section{Methods}

\section{Study design and setting}

This study was a register-based cross-sectional study. The data was collected by consulting the electronic records of patients hospitalized in two divisions of the department of internal medicine of the Geneva University Hospitals (division of general internal medicine and division of general medical rehabilitation) for a total of 11 wards. On a given day, the electronic records of all patients of one of the wards were consulted and data collected by using the computerized patient record system of the Geneva University Hospitals (DPI ${ }^{\circledR}$ ). The whole data collection (all patients of all the wards) was done in the same week, meaning that all the electronic records of a single ward were looked at on the same day but the whole data collection was done over a week. All patients' data was anonymised.

\section{Inclusion criteria}

Patients over 18 years old and hospitalized in either the division of general internal medicine or the division of general medical rehabilitation on the day of the study.

\section{Primary and secondary outcomes}

The primary outcomes was the proportion of patients receiving a PPI at hospital and at home.

The secondary outcome was the adequacy of the indication for a PPI in patients receiving this treatment. Evaluation of the adequacy was done following Table 1.
This table was built taking into account the National Institute of Health and Care Excellence (NICE) guideline "Gastro-oesophageal reflux disease and dyspepsia in adults: investigation and management" [34] for the justified indications and the Swiss Summary of Product Characteristics of the PPIs for the possible justified indications that were not already mentioned in the NICE guideline. We chose the NICE guideline because of the absence of a European or a Swiss guideline. These guidelines have been used to develop internal recommendations in our hospital and so we expected that the Geneva University Hospitals prescribers would follow them.

\section{Statistical analysis}

\section{Data management}

The data was collected anonymously and consisted of collecting "patient" data (gender and age) and "PPI" data (indication, international nonproprietary name (INN), dosage and route of administration, if the treatment was initiated on admission and the evaluation of the adequacy of the treatment).

\section{Statistical strength and data analysis}

This was a cross-sectional study aimed at characterizing the PPI prescription for hospitalized patients on a specific day. There was no hypothesis about the expected value of subjects. The analysis consisted of descriptive statistics separated into several parts, such as "PPI prescription at the hospital" and "PPI treatment at home".

\section{Results}

The total of patients screened and included in this study was 180 and the flowchart is shown in Fig. 1.

The average patient age was 65.7 years old and the distribution of men and women was respectively $53 \%(\mathrm{~N}=95)$ and $47 \%(\mathrm{~N}=85)$.

For patients for whom home treatment was known $(\mathrm{N}=171), 54 \%(\mathrm{~N}=93)$ did not have a PPI at home and $46 \%(\mathrm{~N}=78)$ of patients were already treated at home. Home treatment was undocumented for 9 patients. Among this overall population, $54 \%(\mathrm{~N}=97)$ were treated with a PPI at the hospital. The average age of these patients was 64.4 years. The percentages of men and women was respectively $48 \%(\mathrm{~N}=47)$ and $52 \%(\mathrm{~N}=50)$. No gender or age differences were seen between patient treated by a PPI or not.

Of these 97 patients treated with PPI at the hospital, $29 \%(\mathrm{~N}=28)$ of patients had their PPI treatment initiated at hospital. The most common PPI prescribed was 
Table 1 Classification of indications

Possibly justified treatment with esomeprazole (Swissmedicinfo.ch)

$40 \mathrm{mg} / \mathrm{d}$

Prophylaxis of ulcer recessions associated with Helicobacter pylori (20 mg twice daily for 7 days)

$20 \mathrm{mg} / \mathrm{d}$

Long-term prophylaxis of reflux oesophagitis recurrence

Treatment of symptomatic reflux after disappearance of symptoms, if no NSAID or emergence of new disorders

Justified treatment with esomeprazole (NICE)

$>40 \mathrm{mg} / \mathrm{d}$

Hypersecretion, including Zollinger-Ellison syndrome and idiopathic hypersecretion (40 mg twice daily at the beginning and possible increase at 80 (-120) mg twice daily)

i.v: Treatment and prevention of new haemorrhages of a documented gastric or duodenal bleeding ulcer ( 80 mg in bolus by fast infusion during

$30 \mathrm{~min}$ then $8 \mathrm{mg} / \mathrm{h}$ during $72 \mathrm{~h}$ )

$40 \mathrm{mg} / \mathrm{d}$

Treatment of severe esophagitis ( 8 weeks)

Maintenance treatment for patients with severe esophagitis (if maintenance treatment fails, change with another PPI at full-dose or high-dose)

H. pylori eradication therapy $(2 \times 20 \mathrm{mg}$ for 7 days $)$

Prevention of new haemorrhages of a gastric or duodenal ulcer after treatment with esomeprazole intravenous (4 weeks)

$20 \mathrm{mg} / \mathrm{d}$

If taking a needed NSAID while diagnosed peptic ulcer ( 8 weeks)

Patient with NSAID with peptic ulcer diagnosed ( 8 weeks)

Not investigated dyspepsia (4 weeks)

Treatment of gastroesophageal reflux (4-8 weeks)

Patient with dilation of the oesophagus following stenosis (long term)

Peptic ulcer treatment for patients who are $H$. pylori negative and who are not on NSAIDs (4-8 weeks)

Treatment of functional dyspepsia if $H$. pylori excluded and symptoms persist (4 weeks)

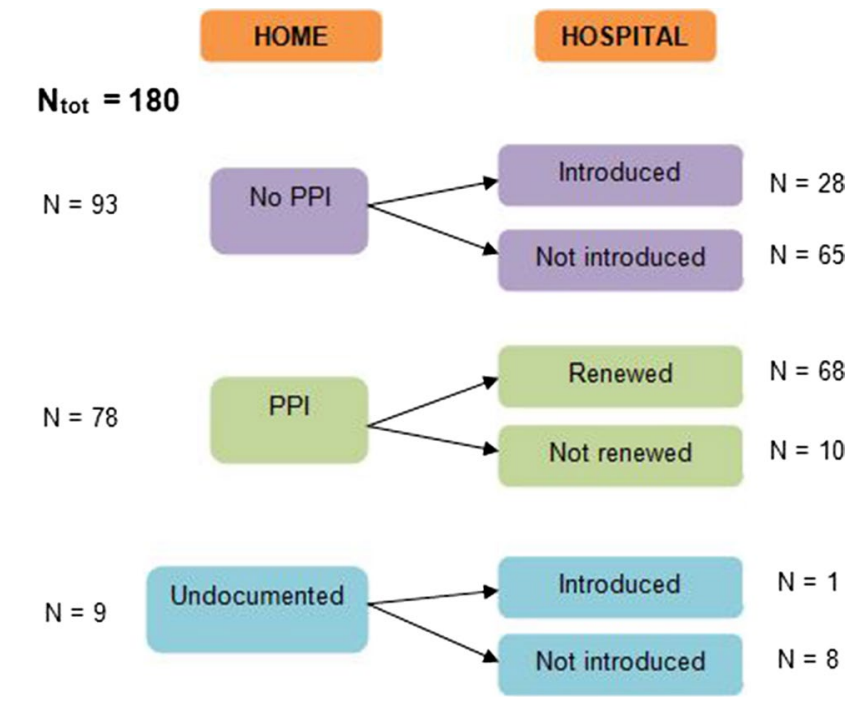

Fig. 1 Diagram of the distribution of patients included

esomeprazole $(97 \%, \mathrm{~N}=94)$, followed by lansoprazole $(2 \%, \mathrm{~N}=2)$ and pantoprazole $(1 \%, \mathrm{~N}=1)$. The predominant route of administration was oral at $94 \%(\mathrm{~N}=91)$, followed by intravenous $(4 \%, \mathrm{~N}=4)$, and perfusion $(2 \%$,
$\mathrm{N}=2$ ). The predominant dosage of esomeprazole was $40 \mathrm{mg} / \mathrm{d}$ in $50 \%$ of cases $(\mathrm{N}=47)$. Other dosages were $20 \mathrm{mg} / \mathrm{d}$ in $35 \%(\mathrm{~N}=33), 80 \mathrm{mg} / \mathrm{d}$ in $12 \%(\mathrm{~N}=11)$, $8 \mathrm{mg} / \mathrm{h}$ in $2 \%(\mathrm{~N}=2)$ and finally $120 \mathrm{mg} / \mathrm{d}$ in $1 \%(\mathrm{~N}=1)$ of patients.

For these same 97 patients, regardless of the dosage, $72 \%(\mathrm{~N}=70)$ of the indications were unjustified, $4 \%(\mathrm{~N}=4)$ were possibly justified and $24 \%(\mathrm{~N}=23)$ were justified in the patient's files. Of these justified and possibly justified indications, 25\% ( $\mathrm{N}=1)$ and $44 \%(\mathrm{~N}=10)$ respectively had an adequate dose. Therefore, in all patients with a PPI at hospital, only $11 \%$ had a justified and possibly justified indication with an adequate dose. The most frequently reported unjustified indication was prophylaxis of bleeding when the patients received also an NSAID, an anticoagulant or an antiplatelet drug with a frequency of $24 \%(\mathrm{~N}=17)$.

Regarding patients that did not have a PPI at home $(\mathrm{N}=93)$, the same $28(30 \%)$ had one initiated on admission. Of these 28 patients, $79 \%(\mathrm{~N}=22)$ of treatments implemented at the hospital had no valid indication, whereas only $21 \%(\mathrm{~N}=6)$ had a justified or possibly justified indication. Of the 65 patients that did not have a treatment initiated at the hospital, $3 \%(\mathrm{~N}=2)$ would have had an indication to receive one. The population which didn't need a PPI and 
didn't have a PPI represents $35 \%(\mathrm{~N}=63)$ of the total of patients screened.

Regarding patients that did have a PPI at home already $(\mathrm{N}=78)$, esomeprazole was the most prescribed $(70 \%$, $\mathrm{N}=54$ ), followed by omeprazole, pantoprazole and lansoprazole with a rate of $20 \%(\mathrm{~N}=16), 9 \%(\mathrm{~N}=7)$ and $1 \%(\mathrm{~N}=1)$ respectively. Oral route was the only one used $(100 \%)$. Regarding the dosage, $40 \mathrm{mg} / \mathrm{d}$ was prescribed in $60 \%(\mathrm{~N}=32)$ of esomeprazole prescription cases, $20 \mathrm{mg} / \mathrm{d}$ in $35 \%(\mathrm{~N}=19)$ and $80 \mathrm{mg} / \mathrm{d}$ in $5 \%(\mathrm{~N}=3)$. Of these, $13 \%$ $(\mathrm{N}=10)$ saw their prescription stopped on admission to hospital. In most cases, documentation available in the admission letter did not allow classifying the home prescriptions as justified, possibly justified or unjustified.

Finally, $87 \%(\mathrm{~N}=68)$ of known home prescriptions were kept on admission and among them only $29 \%(\mathrm{~N}=20)$ were valid because the indication was justified or possibly justified according to the guidelines. It also means that $70 \%$ $(\mathrm{N}=68)$ of hospital PPI prescriptions $(\mathrm{N}=97)$ come directly from home but only $21 \%(\mathrm{~N}=20)$ are for valid indications.

\section{Discussion}

The prevalence of PPI prescription in our hospital is high with more than half the patients on PPI treatment. This is in line with other studies, conducted in the US and in Europe, where the prescription rate can reach up to $80 \%[7,35]$. A study conducted in a Qatari hospital highlighted that the prescription of acid suppressive therapy concerned 53\% of patients and the proportion of PPI and histamine 2 antagonists was $89 \%$ and $11 \%$ respectively [36]. Moreover, $29 \%$ of the prescriptions in our study were new prescriptions initiated on admission to the hospital. This is slightly lower than percentage reported in Villamanan et al. study, where $49 \%$ of patients had a treatment initiated on admission [35].

The most common used PPI at our hospital is esomeprazole with $97 \%$ of patients receiving this drug. This is due to the implementation in our hospital of a restrictive drug formulary aimed at minimizing acquisition costs and limiting the number of medications available in our hospital. Esomeprazole is listed in our formulary and is therefore the reference drug in its therapeutic class. However, the dosage of $40 \mathrm{mg} / \mathrm{d}$, prescribed in $50 \%$ of our patients, has no reasonable explanation other than aiming at an optimal efficacy of a medication with a favourable short-term risk-benefit ratio, from prescribers that prefer to avoid gastric complications whilst ignoring the long-term adverse effects.

Regarding adequacy of the prescription, $89 \%$ were unjustified in the patient file when taking into account the indication and the daily dose, with $72 \%$ having an inadequate indication and a further $17 \%$ having a justified or a possibly justified indication but with an inadequate daily dose.
A study conducted in a French hospital showed that the prescriptions that were not justified as mentioned in the market authorisation of the PPIs were as high as 74\% [5]. The study conducted in a Qatari hospital also highlighted that only $34 \%$ of patients had a justified prescription, PPI and anti-histamine 2 antagonists together [36]. The high rate found in our study can be partly explained by the fact that the Summary of Products Characteristics for PPIs in Switzerland is unprecise and less restrictive than the indications considered justified in our study but shows nevertheless that correct indication and correct dosage are a crucial problem in the prescribing of PPIs. Moreover, when it comes to patients that have a treatment initiated in our hospital, again $89 \%$ receive a PPI for an unjustified indication. A study conducted in Spain reports a rate of only $36 \%$ [36], but again this can be explained by the fact that they were less restrictive on the indications than we were in our study.

Interestingly, nearly half the patients already had a PPI in their treatment on admission to the hospital with $70 \%$ of them treated with esomeprazole and nearly $60 \%$ taking a $40 \mathrm{mg} / \mathrm{d}$ dosage. This confirms the apparent impact of the hospital on the community due to the continuity of care. This influence was demonstrated by a study conducted at the Geneva University Hospitals which showed the extra cost of this continuity of care, because the generics of esomeprazole didn't exist at the time of the study, between 2000 and 2008 [37]. It also demonstrates that general practitioners are prone to over-prescribing this therapeutic class. Among our patients, nearly $90 \%$ saw their prescription of PPI continued on admission ignoring the fact that the indication was justified in only $29 \%$ of patients. The study conducted in the Qatari hospital found that the usage of acid suppressive medication could even worsen with a $12 \%$ of prescription rate before admission to a 53\% during hospitalisation [36]. This is in contradiction with the opportunity that a hospital has to review properly the treatment of the patients. Our study did not aim to quantify the prescription at discharge but the Qatari study showed that this is also a problem. In their study, 54\% of PPIs with a non-justified prescription were still prescribed upon discharge and this rate was still of 50\% six months after discharge [36]. Prescriptions seem not to be reassessed at admission and at discharge and this is a vicious circle which influences prescription in the community and leads to long-term treatments.

A possible explanation of the overuse of PPIs could be the occurrence of rebound acid hypersecretion (RAHS) [4]. RAHS is defined as an increase in gastric acid secretion above pre-treatment levels after anti-secretory therapy. It leads to acid related symptoms such as heartburn, acid regurgitation, and dyspepsia. The acid rebound hypersecretion seems to be caused by an increased acid secretion by proton-pump stimulation due to a compensatory gastrin release and an hypertrophy of enterochromaffine-like cells through 
an increased level of chromogranin A [37-40]. A study from 1996 reports that the gastric acid secretory capacity was increased by $22 \% 14$ days after discontinuation of a 3 -month course of omeprazole $40 \mathrm{mg} / \mathrm{d}$ [38]. Some studies demonstrate that the discontinuation of PPI is a success in only 19 to $27 \%$ of long-term PPI users, after 12 months [41, 42]. Also, discontinuation is most successful when patients have no gastro-oesophageal reflux disease [42]. The success of PPI discontinuation in patients with inappropriate indications is a major health concern in the light of the number of patients receiving an inappropriate and long-term prescription and the associated excessive health care costs $[43,44]$. The discontinuation of PPI is not easy. Bjornsson and al. [41] suggested to use a gradual discontinuation of PPI in order to prevent the consequence of the acid rebound effect. However, they failed to show a different rate of discontinuation between patient in the group with abrupt discontinuation and in the group with gradual discontinuation. The authors conclude that a gradual weaning of the PPI might be useful only in the rare patients with hypergastrinemia. At the present time, the level of evidence is not sufficient to recommend a method of PPI withdrawal.

Another approach against PPI overuse was evaluated in a prospective study. The approach was a multi-approach strategy through an audit and feedback method, the implementation of a usage guideline for medical inpatients, the diffusion of a logarithmic chart on the proper usage of acid suppressive medications for medical inpatients from admission through to discharge and the participation of clinical pharmacist in the multidisciplinary rounds [45]. This approach allowed decreasing the inappropriate use of acid suppressive therapy. There was a $51 \%(p<0.0001)$, a $62 \%$ $(p<0.0001)$ and a 67\% $(p=0.0008)$ decrease of inappropriate use during admission, at discharge and at the two months follow-up visit, respectively [45].

Our study has some limitations. First, due to the study's methodology, our analysis was limited by the quality of the documentation of the patients' records in the computerized patient record system of our hospital. Secondly, often, at times, assumptions had to be made about the indication because this was not explicitly documented. It was by studying concomitant medication, gastroenterological examinations and medical history that indications, valid or otherwise, were presumed. Finally, we did not collect any data on PPI prescription at discharge that would have given us an idea of the community prescription.

\section{Conclusion}

Our study, conducted in a tertiary care hospital in Switzerland, highlights the problems surrounding the prescription of PPIs. These problems are multifactorial and the solutions should therefore be addressed from different angles. Improving prescribers' awareness of the over-use of PPIs and the long-term adverse effects as well as setting up guidelines in our hospital would be a first step in minimizing the overuse of this therapeutic class. Guidelines built on evidence-based indications and adequate daily doses would help the prescribers, in the hospital and in the community, to adequately prescribe and reduce misuse of PPIs. Integration of a prescription assistance programme in our computerized patient record system could help to identify the correct indication and the correct dose and limit the length of prescription.

Also, when admitted to the hospital, patients should benefit from a thorough evaluation of their treatment according to their clinical utility and at discharge, reconsideration of the usefulness of the hospital treatment should also be considered.

Finally, education and patient awareness could also significantly reduce the use of PPIs, especially in the long term.

This study was a pragmatic real-life study. The medical structure in which it was conducted and the patient's characteristics should allow our results to be extrapolated to other general inpatient medical wards in Swiss teaching hospital. The Geneva University Hospital being one of the five university hospitals in Switzerland and the largest one, data from this study could be of value for other countries also.

All procedures performed in our study were in accordance with the ethical standards of the regional research ethics committee of the canton of Geneva (No 2016-00580) and with the 1964 Helsinki declaration and its later amendments or comparable ethical standards.

Funding This research did not receive any specific grant from funding agencies in the public, commercial, or not-for-profit sectors.

Conflicts of interest The authors declare that they have no conflict of interest.

Open Access This article is distributed under the terms of the Creative Commons Attribution 4.0 International License (http://creativeco mmons.org/licenses/by/4.0/), which permits unrestricted use, distribution, and reproduction in any medium, provided you give appropriate credit to the original author(s) and the source, provide a link to the Creative Commons license, and indicate if changes were made.

\section{References}

1. George CJ, Korc B, Ross JS. Appropriate proton pump inhibitor use among older adults: a retrospective chart review. Am J Geriatr Pharmacother. 2008;6(5):249-54.

2. Sukhovershin RA, Cooke JP. How may proton pump inhibitors impair cardiovascular health? Am J Cardiovasc Drugs. 2016;16(3):153-61 
3. Rotman SR, Bishop TF. Proton pump inhibitor use in the U.S. ambulatory setting 2002-2009. PLoS ONE. 2013;8(2):e56060.

4. Roulet L, Vernaz N, Giostra E, Gasche Y, Desmeules J. Adverse effects of proton pump inhibitors: should we worry about longterm exposure? Rev Med Interne. 2012;33(8):439-45.

5. Marie I, Moutot A, Tharrasse A, Hellot M-F, Robaday S, Hervé F, et al. Validity of proton pump inhibitors' prescriptions in a department of internal medicine. Rev Med Interne. 2007;28(2):86-93.

6. Nardino RJ, Vender RJ, Herbert PN. Overuse of acid-suppressive therapy in hospitalized patients. Am J Gastroenterol. 2000;95(11):3118-22.

7. Redfern RE, Brown M, Karhoff KL, Middleton JL. Overuse of acid-suppression therapy at an Urban Tertiary Hospital. South Med J. 2015;108(12):732-8.

8. Liste « Top $5 »-$ pierre angulaire de la campagne « Smarter Medicine $\gg \mid$ smartermedicine.ch [Internet]. [cited 2016 Mar 23]. Available from: http://www.smartermedicine.ch/fr/liste-top-5.

9. Cook DJ, Witt LG, Cook RJ, Guyatt GH. Stress ulcer prophylaxis in the critically ill: a meta-analysis. Am J Med. 1991;91(5):519-27.

10. Bez C, Perrottet N, Zingg T, Leung Ki E-L, Demartines N, Pannatier A. Stress ulcer prophylaxis in non-critically ill patients: a prospective evaluation of current practice in a general surgery department. J Eval Clin Pract. 2013;19(2):374-8.

11. Scheiman JM, Yeomans ND, Talley NJ, Vakil N, Chan FKL, Tulassay Z, et al. Prevention of ulcers by esomeprazole in at-risk patients using non-selective NSAIDs and COX-2 inhibitors. Am J Gastroenterol. 2006;101(4):701-10.

12. Gray SL, LaCroix AZ, Larson J, Robbins J, Cauley JA, Manson JE, et al. Proton pump inhibitor use, hip fracture, and change in bone mineral density in postmenopausal women: results from the Women's Health Initiative. Arch Intern Med. 2010;170(9):765-71.

13. Laine L. Proton pump inhibitors and bone fractures? Am J Gastroenterol. 2009;104(Suppl. 2):S21-6.

14. Targownik LE, Goertzen AL, Luo Y, Leslie WD. Long-term proton pump inhibitor use is not associated with changes in bone strength and structure. Am J Gastroenterol. 2017;112(1):95-101.

15. Harding BN, Weiss NS, Walker RL, Larson EB, Dublin S. Proton pump inhibitor use and the risk of fractures among an older adult cohort. Pharmacoepidemiol Drug Saf. 2018;27(6):596-603.

16. Herzig SJ, Howell MD, Ngo LH, Marcantonio ER. Acid-suppressive medication use and the risk for hospital-acquired pneumonia. JAMA. 2009;301(20):2120-8.

17. Laheij RJF, Sturkenboom MCJM, Hassing R-J, Dieleman J, Stricker BHC, Jansen JBMJ. Risk of community-acquired pneumonia and use of gastric acid-suppressive drugs. JAMA. 2004;292(16):1955-60.

18. Dial S, Delaney JAC, Barkun AN, Suissa S. Use of gastric acidsuppressive agents and the risk of community-acquired Clostridium difficile-associated disease. JAMA. 2005;294(23):2989-95.

19. Howell MD, Novack V, Grgurich P, Soulliard D, Novack L, Pencina $\mathrm{M}$, et al. Iatrogenic gastric acid suppression and the risk of nosocomial Clostridium difficile infection. Arch Intern Med. 2010;170(9):784-90.

20. Leonard J, Marshall JK, Moayyedi P. Systematic review of the risk of enteric infection in patients taking acid suppression. Am J Gastroenterol. 2007;102(9):2047-56.

21. Imhann F, Bonder MJ, Vich Vila A, Fu J, Mujagic Z, Vork L, et al. Proton pump inhibitors affect the gut microbiome. Gut. 2016;65(5):740-8.

22. Jackson MA, Goodrich JK, Maxan M-E, Freedberg DE, Abrams JA, Poole AC, et al. Proton pump inhibitors alter the composition of the gut microbiota. Gut. 2016;65(5):749-56.

23. Johnson DA, Katz PO, Armstrong D, Cohen H, Delaney $\mathrm{BC}$, Howden $\mathrm{CW}$, et al. The safety of appropriate use of over-the-counter proton pump inhibitors: an evidence-based review and delphi consensus. Drugs. 2017;77(5):547-61.

24. Torpey N, Barker T, Ross C. Drug-induced tubulo-interstitial nephritis secondary to proton pump inhibitors: experience from a single UK renal unit. Nephrol Dial Transpl Off Publ Eur Dial Transpl Assoc Eur Ren Assoc. 2004;19(6):1441-6.

25. Härmark L, van der Wiel HE, de Groot MCH, van Grootheest AC. Proton pump inhibitor-induced acute interstitial nephritis. Br J Clin Pharmacol. 2007;64(6):819-23.

26. Koop H, Bachem MG. Serum iron, ferritin, and vitamin B12 during prolonged omeprazole therapy. J Clin Gastroenterol. 1992;14(4):288-92.

27. Termanini B, Gibril F, Sutliff VE, Yu F, Venzon DJ, Jensen RT. Effect of long-term gastric acid suppressive therapy on serum vitamin B12 levels in patients with Zollinger-Ellison syndrome. Am J Med. 1998;104(5):422-30.

28. Cheung KS, Chan EW, Wong AYS, Chen L, Wong ICK, Leung WK. Long-term proton pump inhibitors and risk of gastric cancer development after treatment for Helicobacter pylori: a population-based study. Gut. 2018;67(1):28-35.

29. Palmer RH. Use of proton pump inhibitors and risks of fundic gland polyps and gastric cancer: systematic review and metaanalysis. Clin Gastroenterol Hepatol. 2017;15(5):790.

30. Li X-Q, Andersson TB, Ahlström M, Weidolf L. Comparison of inhibitory effects of the proton pump-inhibiting drugs omeprazole, esomeprazole, lansoprazole, pantoprazole, and rabeprazole on human cytochrome P450 activities. Drug Metab Dispos Biol Fate Chem. 2004;32(8):821-7.

31. Würtz M, Grove EL, Kristensen SD, Hvas A-M. The antiplatelet effect of aspirin is reduced by proton pump inhibitors in patients with coronary artery disease. Heart Br Card Soc. 2010;96(5):368-71.

32. Othman F, Card TR, Crooks CJ. Proton pump inhibitor prescribing patterns in the UK: a primary care database study. Pharmacoepidemiol Drug Saf. 2016;25(9):1079-87.

33. Vernaz N, Haller G, Girardin F, Huttner B, Combescure C, Dayer $\mathrm{P}$, et al. Patented drug extension strategies on healthcare spending: a cost-evaluation analysis. PLoS Med. 2013;10(6):e1001460.

34. Gastro-oesophageal reflux disease and dyspepsia in adults: investigation and managementl Guidance and guidelines| NICE [Internet]. [cited 2018]. https://www.nice.org.uk/guidance/cg184.

35. Villamañán E, Ruano M, Lara C, Suárez-de-Parga JM, Armada E, Álvarez-Sala R, et al. Reasons for initiation of proton pump inhibitor therapy for hospitalised patients and its impact on outpatient prescription in primary care. Rev Esp Enferm Dig. 2015;107(11):652-8.

36. Khudair IF, Sadik ND, Hanssens YI. Prescribing pattern of acid suppressive medications for medical inpatients in a teaching hospital in Qatar. Saudi Med J. 2009;30(1):125-9.

37. Sanduleanu S, Stridsberg M, Jonkers D, Hameeteman W, Biemond I, Lundqvist G, et al. Serum gastrin and chromogranin A during medium- and long-term acid suppressive therapy: a case-control study. Aliment Pharmacol Ther. 1999;13(2):145-53.

38. Waldum HL, Arnestad JS, Brenna E, Eide I, Syversen U, Sandvik AK. Marked increase in gastric acid secretory capacity after omeprazole treatment. Gut. 1996;39(5):649-53.

39. Laine L, Ahnen D, McClain C, Solcia E, Walsh JH. Review article: potential gastrointestinal effects of long-term acid suppression with proton pump inhibitors. Aliment Pharmacol Ther. 2000;14(6):651-68.

40. Waldum HL, Sandvik AK, Syversen U, Brenna E. The enterochromaffin-like (ECL) cell. Physiological and pathophysiological role. Acta Oncol Stockh Swed. 1993;32(2):141-7.

41. Björnsson E, Abrahamsson H, Simrén M, Mattsson N, Jensen C, Agerforz $\mathrm{P}$, et al. Discontinuation of proton pump inhibitors in 
patients on long-term therapy: a double-blind, placebo-controlled trial. Aliment Pharmacol Ther. 2006;24(6):945-54.

42. van der Velden AW, de Wit NJ, Quartero AO, Grobbee DE, Numans ME. Pharmacological dependency in chronic treatment of gastroesophageal reflux disease: a randomized controlled clinical trial. Digestion. 2010;81(1):43-52.

43. Lassen A, Hallas J, Schaffalitzky De Muckadell OB. Use of antisecretory medication: a population-based cohort study. Aliment Pharmacol Ther. 2004;20(5):577-83.

44. Forgacs I, Loganayagam A. Overprescribing proton pump inhibitors. BMJ. 2008;336(7634):2-3.
45. Khudair IF, Sadik ND, Hanssens Y, Muhsin SA, Matar I. Impact of multi-approach strategy on acid suppressive medication use in a teaching hospital in Qatar. Int J Clin Pharm. 2011;33(5):763-71.

Publisher's Note Springer Nature remains neutral with regard to jurisdictional claims in published maps and institutional affiliations. 